\title{
Enhancing Urban Heritage: Industrial Culture and Cultural Industry
}

\author{
By Esther Giani* \\ Giancarlo Carnevale
}

The rehabilitation of historical centres in Italy offers a vast quantity of experiences, though the concept of preserving urban and architectural heritage is quite recent. In fact the same experience does not find place for industrial districts or areas. The scale of intervention is specific to each case as it deals with single artefacts as well as complex building systems, open spaces and urban closeness. The heterogeneity of adopted methods is a result of diverse contextual conditions and, perhaps above all, diverse urban policies. An initial distinction must be made between Monument and Document, thus distinguishing two levels, both equally relevant to the preservation of the identities of a site, though of widely varying origins and - quite often - diverse physical, formal and functional consistency. This text will examine primarily those aspects related to urban morphology, looking at buildings by means of the Vitruvius paradigm: firmitas, utilitas and venustas. These notions will, however, be subordinated to superior levels of programming. Political choices determine what can be pursued, while economic strategies indicate the limits of each intervention; last but not least is the notion of environmental sustainability in its broadest meaning that encompasses issues of energy, economics, function, technology and, above all, society. We will attempt to further narrow the field by considering the rehabilitation of a complex industrial district: the first methodological choice concerns the type of analysis (the reading) adopted to acquire notions useful to the development of a concept design. Architectural debate, in particular in Italy, was witness to the articulated development of diverse positions. A rich selection produced a number of fixed points that will be synthetically referred to. We shall expose the case of Porto Marghera, the Venice industrial district: readings and studies developed within our university research unit and with the help of research-fellows, degree students, phd students.

${ }^{*}$ Researcher, Iuav University of Venice, Italy.

†Professor, Iuav University of Venice, Italy. 


\section{Introduction and Theoretical Background}

Signs of man are everywhere on the territory; rare places are still 'natural'. Man's marks are so omnipresent as to induce the Nobel Prize in chemistry, Paul Crutzen, to coin a new term to define the current geological era: Anthropocene. Man has by now changed environment, climate and landscape.

Uncontrolled urbanization, particularly accentuated in Italy, led to sacrificing large portions of territory and producing harmful consequences on the environment. Only in the last decade a greater awareness, even in territorial policies, is emerging to define new strategies for the maintenance of the architectures heritage and in the protection of the landscape. One of the themes that seems to emerge concerns modifying the criteria for evaluating new interventions: the crude cost-benefit ratio has undergone a major overhaul. Costs refer to those of specifications and price tables, but also to those regarding $\mathrm{CO}^{2}$ emissions, social impacts, ecological footprint, to the consequences for the environment, etc. This changed perspective calls for new skills and recalls those lines of research formerly placed on the side-lines and now recognised as strategic.

The conservation and preservation of existing buildings now extends beyond monumental heritage, to include everything that has been built, that is to say the anthropized territory, the infrastructures, included the industrial areas (Figure 1). We are merely alluding here to an issue that has been long discussed by historians, particularly by historians of material culture: the distinction between monument and document ${ }^{1}$ becomes less apparent when introducing the time parameter (which is 'crucial' for physicists). Referring to time: what can make a simple tavern valuable? A few thousand years: just the time to give a Coca Cola bottle cap a priceless archaeological value. This trivial reflection involves other considerations, which are far from innocent, for example: what is left of Mary Quant's London²? A few photos, few films, some

\footnotetext{
${ }^{1}$ 'Collective memory and its scientific form, history, apply to two types of materials: documents and monuments. In fact, what survives is not the complex of what existed in the past, but a choice implemented both by the forces operating in the temporal evolution of the world and of mankind, and by those who are delegated to study the past and past times, historians. Such materials of memory can come in two main forms: monuments, heritage of the past, and documents, the historian's choice'. (Le Goff, J. 1978. Documento/Monumento [Monument/Document]. Enciclopedia Einaudi, Turin (Italian), vol. V, pp. 38-43). And more: 'The notion of material culture appeared in the humanities, particularly history, following the establishment of anthropology and archaeology, and the influence exerted by historical materialism. (...) The study of material culture (...) dedicates itself to repeating facts, not to the event; it does not deal with superstructure, but infrastructure. (...) Material culture tends to build a bridge towards man's imagination and his creativity and to consider its three fundamental components: space, time and the sociality of the objects. Even though it remains to be defined with more accuracy, and even though there is still some ambiguity, the study of material culture belongs to historical research, and collaborates with its method to retrace the spirals that every ruin of the past brings about.' (Bucaille, R., Pesez, J.M. Cultura materiale [material culture]. Enciclopedia Einaudi, op cit, Vol. V. IV, p. 271-305).

${ }^{2}$ Mary Quant, English fashion designer, born in London in 1934, famous for inventing the miniskirt, became a symbol of the 1960s, associated with the Beatles and the revolution of morals and habits that struck European and world society of that time.
} 
shops, preserved or rebuilt in the style of that age, but the urban environment, the billboards, the signage, the furniture, the Zeitgeist (the spirit of the time), have hopelessly vanished. This continuous urban renewal, the cancellation of material traces of everyday life, is a normal metabolic process that accompanies our history and that it is unreasonable to oppose. Otherwise, we should begin to ask ourselves the question of the evidence of the past through the preservation of places, things and artifacts, and finally, what the atmosphere characterize and describe the identity of a time. We elaborate these thoughts and reach an evaluation judgment with objects, at various levels, from milionaire auctions by Sotheby's and Christie's to cheap antiques and local junk dealers. The past has an enduring fascination: it is a resource that we tend to overlook. The zeitgeist wafts through the objects, but not in places, which are irretrievably altered.

Figure 1. Venice and its Hinterland. Facing the Lagoon (and Historic Venice) the Industrial District of Porto Marghera

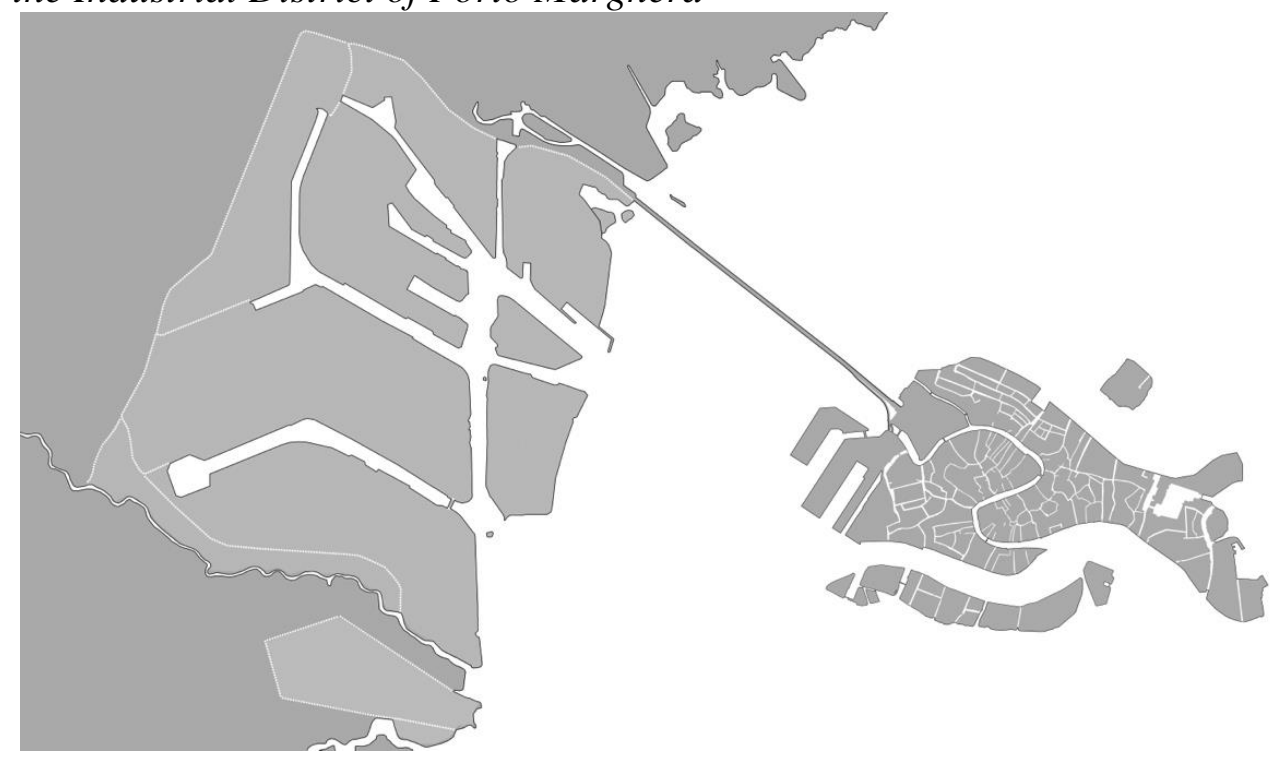

\section{Industrial Landscape: Anatomical Findings}

We used the initial note to introduce a theme, that of the industrial landscape, which many have addressed and different views, creating quite a few conceptual traffic jams: from the misunderstanding of industrial archaeology to the technicalities of reclamation, to the highly artificial nature of some backdrops. In analysing the characteristics of an industrial landscape and in our case it appears inevitable to refer to Porto Marghera ${ }^{3}$, which

\footnotetext{
${ }^{3}$ Porto Marghera, the industrial district of Venice (Italy). At the beginning of the XX century the port of Venice was the second largest in Italy after that of Genoa, but its expansion required ever more space. The diversification of trade and the processing of raw materials made evident the need to create a haven of support on land that would host the traffics of oil and coal and also use the rail transport that was developing. The chosen area was South of Mestre: Porto
} 
moreover is one of the largest industrial areas in Europe - it is difficult to ignore the strongly scenographic connotation that, also thanks to film and advertising over time, imposes itself as a palimpsest of iconologies now rooted in the collective imagination. Going beyond the inescapable suggestion of the bleak prospects - internal and external - that industrial settlements enact, we pledged to develop a morphological analysis based on rigorous methods of detection and observation during nearly two decades of teaching and research trials.

Among the identifying characteristics that have been recorded - in particular at Porto Marghera - but which are surely sufficiently general enough to be extended to nearly all industrial areas, we will try to name a few, in the belief that they constitute an indispensable point of departure in order to formulate any hypothesis of intervention and transformation.

First of all the issue of scale: just look at a map of Porto Marghera to see how the industrial fabric, which is similar to the lines on a map drawn in an urban residential area, actually differs from them due to the immensity both of the buildings and the road network (Figure 2). A genetic mutation made necessary by the different functionalities that exist there (or that have existed there): large squares for handling, storage and parking, wide roadways to accommodate heavy traffic and sets of tracks, widened streets to handle the rotations of elevators and cranes, containers with a simplified morphology due to constructive techniques used, based on sections with drawn profiles, with a vaulted roof or shed, which have become universal icons, along with stylized factory chimneys, for the pictograms representing the industrial areas. Other material signs that strongly characterize such areas are cylindrical or spherical silos, cooling towers and flues.

\footnotetext{
Marghera. The area was part of the Venice lagoon system with a marshy land, an undefined border between land and the lagoon. It took many years to reclaim the area, dig docking channels and stabilize the necessary docks functional to the port. The creation of the first industrial area was proposed and designed by Giovanni Volpi. In 1922, it was also approved the project for the urban settlement of the city-garden of Marghera, subsidiary choice to the district to accommodate the masses of new employees coming from the countryside and from all over Italy to provide manpower to the established industries. The main activity of the industrial area of porto Marghera was basic chemical production (especially fertilizers) that was immediately followed by oil processing and the petrochemical chain; to these activities logistic and service-related activities (shipbuilding) were initially added and by now they almost completely substituted the former ones. Currently, although the productions related to the transformation of oils have not completely ceased, and the logistics services remain and grows, activities related to the arrival of international shipments of goods (Port of Venice) are reconfiguring the geography of Porto Marghera. Today about half of Porto Marghera is disused as production area, which does not correspond to an equal divestiture of its business activities (basically the activity uses half of the space and keeps the rest as dismissed).
} 
Figure 2. Portion of Porto Marghera, when the Industrial District Meets the Garden City. It Is to Show how the Industrial and Dwelling Area Differ due to the Immensity Both of the Buildings and the Road Network

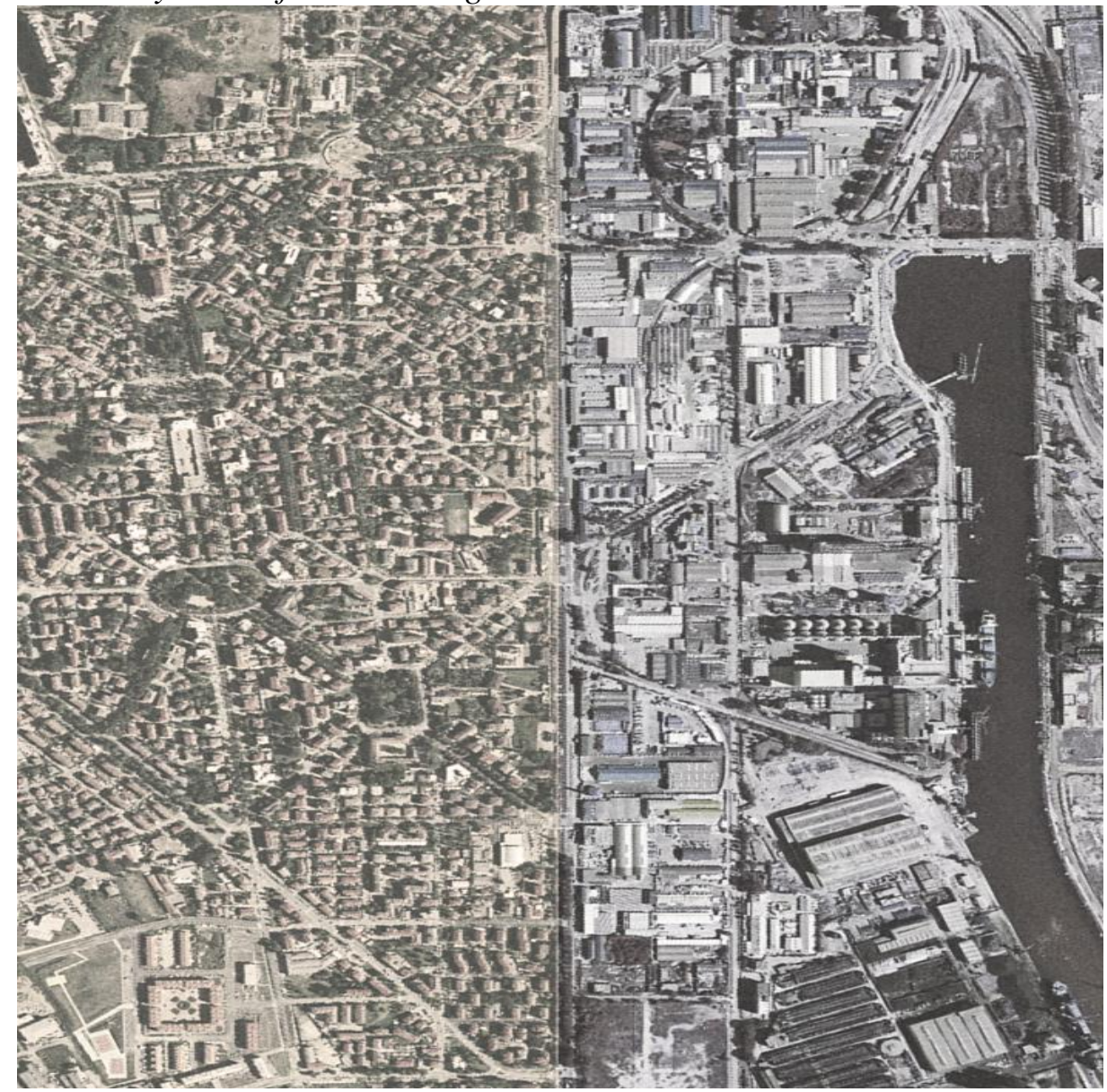

These elements have been, over time, the subject of an increasingly welldefined classification, including, for example, minor morphological characteristics, elusive in a preliminary observation. We refer to perimeter fencing systems, linear profiles that trace a diagonal horizon in perspective shots, or lighting elements (very different from those in urban areas in terms of power and size). But also the paths of the tracks and - and Porto Marghera differs from other industrial areas due to its peculiar artificial origin - the fondamenta, which are the large docks that develop throughout the area, bringing 'arms' of lagoon, stiffened in the geometries now dictated by public transport, close to the factories. Service channels, to be sure, but still capable of reproducing the eternal lie of the reflection, thus adding a further dimension, illusory and virtual, to the broken profile of the man-made elements.

The cataloging, done part by part, identified and geolocated, gathered initially in charts, allowed us to develop real anatomical atlases seeking to tell the shapes of the industrial landscape, by listing them in collections of signs (Figure 3). An analysis that inevitably - though apparently intentionally, in this case - seems marred by a planning prejudice. The narration of the figures 
present in the artificial landscape of Porto Marghera counts as a repertoire, a collection to be used to develop compositional reflections about combination possibilities. Elements of potential scenarios where it is still possible to capture the Zeitgeist.

Figure 3. Porto Marghera: Abacus of the Areas, Atlas of the Buildings for Future Scenarios (Form the Thesis Work by D. Battilana, W. De Marchi, D. Scomparin Presented in March 2014. Relator: E. Giani, Co-Relator: E. Giani)

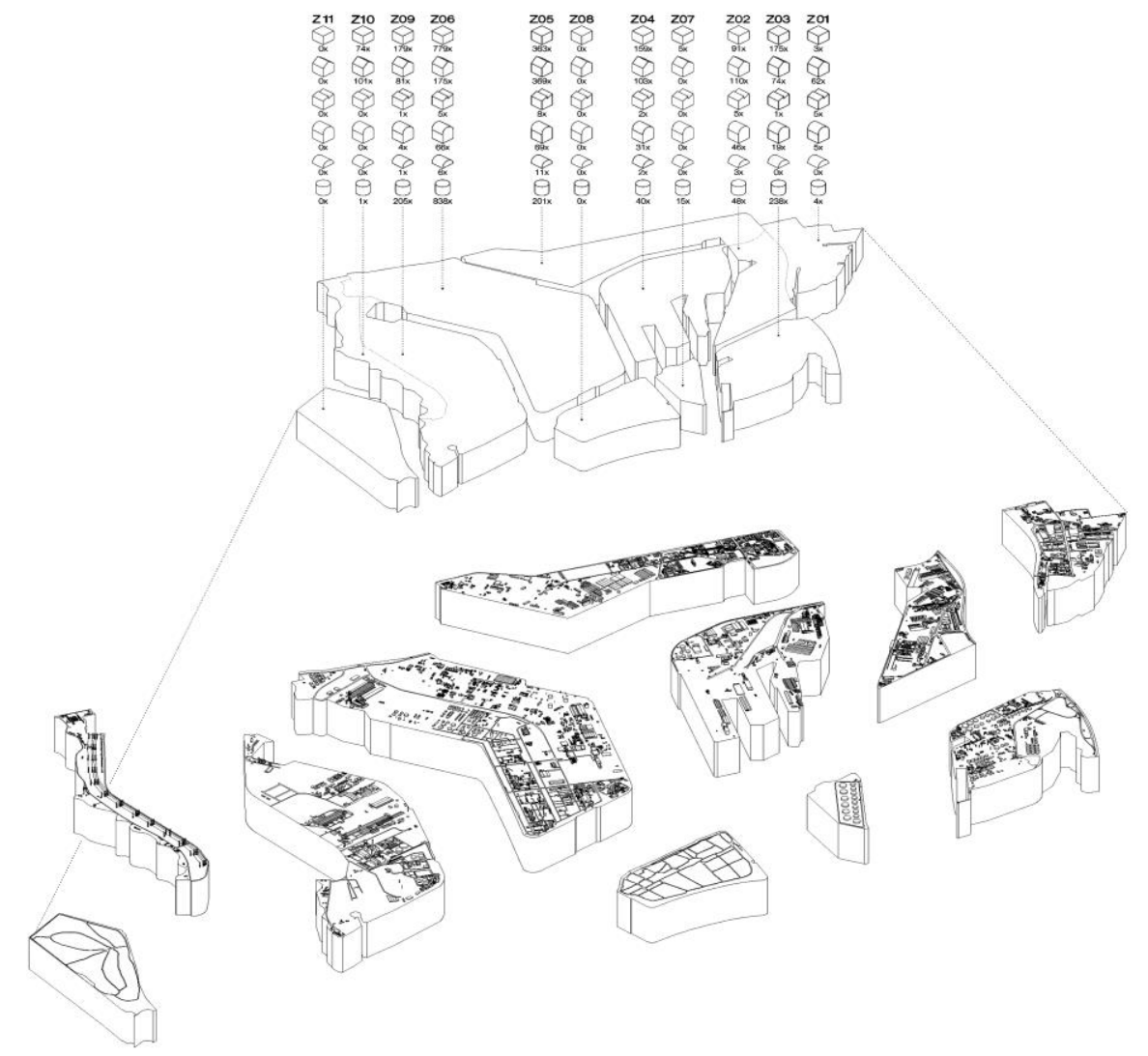

Com-pose ...

The planning prejudice to which we have referred, starts from a deeprooted conviction, based on longstanding theoretical considerations and critiques $^{4}$ : in a nutshell, it is possible to consider each planning process as the development of a rational reflection, as the process of an elaborate compromise between Firmitas, Utilitas and Venustas.

Let's start from an action of will, one that is considered unremarkable in its aftermath, and therefore, legitimized in expressing itself as a free initial starting point ${ }^{5}$. Following further developments, an operational strategy was developed: it's an addressing working methods, otherwise we would no longer

${ }^{4} \mathrm{G}$. Carnevale has written extensively on the subject (in italian), citing, for example: 1993. Caro studente ti scrivo, Milan; 2004. Litanie e griffonage, Rome.

${ }^{5}$ Kant's suggestion is no exception: the initial 'gesture of freedom' and the determinism that goes with it. 
be speaking of a theoretical matter, but a poietic one ${ }^{6}$. It is to take the assemblage of parts as a compositional procedure, safeguarding above all the sustainability and functional consistency of the various options.

One matter is to emphasize, however: that Zeitgeist which was mentioned before, by no means resides in musealising places, in reducing industrial spaces to inflexible spaces. The strong place-type characterization should certainly be preserved, but it is essential to introduce vital functional elements that can legitimize the material persistence of large containers, widened streets and powerful infrastructure. With no real, integrated use, one linked to the needs expressed by a social - and economically sustainable - demand, every operation to defend and preserve places appears foolish and idealistic (Figure 4).

Figure 4. Mario Sironi, The Gasometer (Oil on Canvas, 1943). The Painting is at the Modern and Contemporary Art Museum of Rovereto (Italy)



\section{Compensating}

Mending a rip or a cut, but also compensating for damage: the usual term is compensating for damages incurred. The (Italian) politics, urged also by the financial crisis and by the attitudes of intolerance and greater vigilance and participation that the community is taking, shows more attention to environmental protection. It posits, also due to reduced resources, the theme of regenerating the existing building heritage. The places where the harshest social conflicts have appeared in the recent past are precisely those in the industrial areas, the scene of union struggles, wokers' battles, and of uncontrolled environmental violence as well. Today the rehabilitation of abandoned industrial areas seems to take on also a symbolic meaning, one of redemption, of reappropriation, of reconciling past conflicts. This theme could

\footnotetext{
${ }^{6} \mathrm{G}$. Perec (1936-1982) argued that the way in which intellectual processing develops describes us much better than the result produced. See OuLiPo Ouvroir de litterature potentielle (http://oulipo.net/)
} 
become central, especially for local governments, if combined with a policy of relaunching the production of immaterial goods, in the same places where industrial production thrived.

Figure 5. Porto Marghera. The Diagram Shows the Investments that Should be Done by the Owners Only to Reclaim the Area for Further Public Activities. According to Current Lows and Timing (Form the Thesis Work by D. Battilana, W. De Marchi, D. Scomparin Presented in March 2014. Relator: E. Giani, Co-Relator: I. Peron)

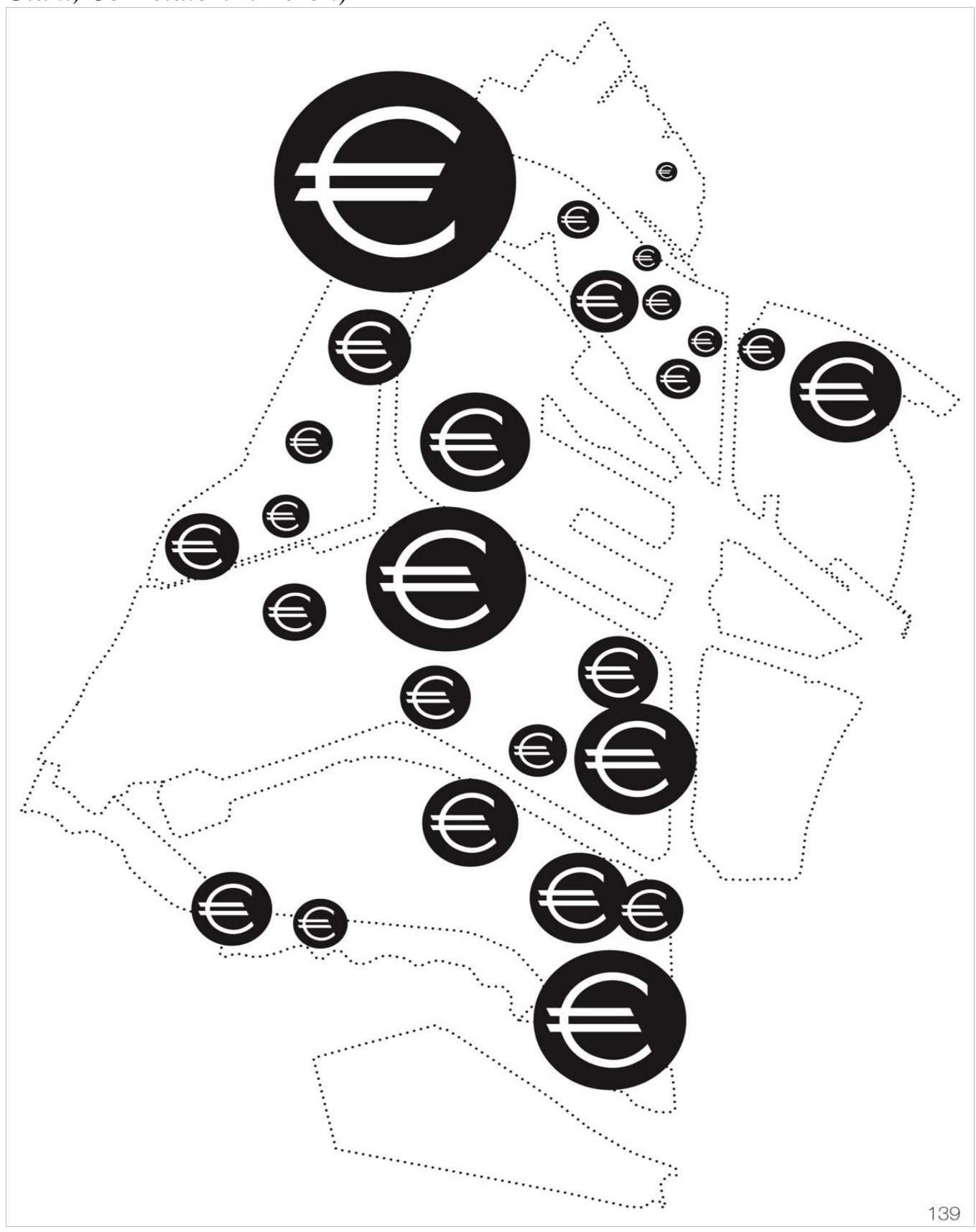


But beyond the virtuous interpretations that we can give these compensations, there is a reality that, as an inescapable historical force, has structural deep motivations: the encounter between social opportunity and economic advantage: business and the common good must find a mutual balance (Figure 5).

In a more comprehensive sense of the term sustainability - an abused semantic container omnibus - it's meaning as indicating the attractiveness for financial investment cannot be excluded. Therefore each remodeling, reclamation, remediation and rehabilitation of industrial areas, will always find its (perhaps main) motivation in an advantageous financial transaction.

\section{Common Good}

Another expression of chameleonic use, often abused by Italian politicians, but inevitably changing over time: the common good for a $19^{\text {th }}$ century community may seem incomprehensible today. Not to mention the different interpretations of this term in relation to geographical, rural and urban settlements. However, in recent years, this ambiguity tended to suggest a common result. In contemporary society an attention and a growing curiosity are emerging regarding a common good; common good formerly precluded to the little bourgeois world. The demand for culture and interest in aesthetic values seem to be configuring a new market. It is a demand that struggles to be channeled because it emerged suddenly and confusingly: we are probably facing with an anthropological variation linked to the sudden evolution of communication, and with the irruption of digital realm. The desire for Beauty, for access to an aesthetic universe that in the not too far off past was reserved to a few privileged social classes, is also flaring up in areas of civil life, in cities and squares, in urban space. The quality of the environment in which one works, and in which one lives, is perceived as a value. We are still lacking the cultural tools that can allow people's imagination to grasp the correct parameters for evaluation. One notices this cultural shift: the demand, that is, for an aesthetic dignity in common living places. We think that it is precisely these new horizons that may suggest strategies for the recovery of industrial areas: to welcome the new needs of the community and meet the economic logics that preside over each resource investment, whether public or private.

\section{Ikea Generation}

A very brief digression, but essential at this point of our reflection: Italy in particular complains about a disconnection, severe and poorly analysed, between the Disciplinary Culture and Popular Culture. The city and the architecture proposed by High Culture are rejected, while by now an imaginary aesthetic has become established, one widely shared, particularly in living areas, and consolidated and fixed in rigorous linguistic parameters, applied by the commercial production of residential housing. This phenomenon, surely an expression of a subculture, but a winning subculture, is evident throughout the Italian national territory. It's widely diffused and, even more disturbing, with a lexical consistency, limited and recurring, which appears to continue and 
traverse entire decades without showing any changes ${ }^{7}$. In a context that leads one to reflect on the many responsibilities not only of the professional class, but also those of entrepreneurial, academic and political classes, we must record the positive signals coming from the world of art and, unexpectedly, from that of trade. We observe how, in just a few years, the taste for the domestic and interior landscape, changed profoundly. In less than a generation, the Ikea-taste has monopolized the generalized interest with an aggressive commercial policy and a decent attention to design quality. This is exactly what Architecture in these decades failed to achieve: to obtain the approval of its audience, to regain the popularity of the project.

Marketing: the contemporary culture of interior furnishings has been released, making notable inroads even in the most marginalized cultural peripheries and overturning a rooted system of aesthetic values. The need for Beauty, long abandoned to a progressive decline, is oriented and rehabilitated through an unexpected short-circuit that sees the logic of the market and cultural redemption in harmony.

This digression is helpful for us to introduce a possible scenario, one with wider margins, but which, however, seems to apply nicely right in the theme of the recovery of industrial areas.

\section{Culture as Beauty}

Culture as beauty and vice versa. A model that seems to contain many references to the current situation. The crisis creates economic insecurity, but also stirs a dulled sensibility, an attention to the decoration of places, the disdain for degraded environments, for contempt and neglect, awakens a sense of Beauty. The new statement is demanding interventions that not only mitigate the damage, but introduce new quality into an environment where one lives (Figure 6). The winding lines at art exhibitions, the popular uprisings against environmental damage, mass pilgrimages to art cities, are indicators calling for our attention. To restore to communities not only environmental quality, but the awareness of living in spaces that represent new cultural frontiers, where it is possible to be immersed in a generalized and accessible quality. It is not just

\footnotetext{
${ }^{7}$ By Giancarlo Carnevale we recall: 1984. L'architettura perde per distacco [The architecture loses for posting]. In «Confronto» n. 3; 1984. Il grottesco prossimo venturo [The grotesque near future]. In Canestrari, M., (edited by), Architettura e forma urbana [Architecture and urban form], Neaples; 1989. Deformazioni ai margini [Deformation of the edge]. In «Op.cit.» n.76; 1993. Grottesco [Grottesque]. Definition for the Dizionario illustrato delle voci più utili all'architetto moderno [Picture dictionary of the terms most useful for modern architect], edited by L. Semerani, Bologna; 1995. Inutilitas, infirmitas, foeditas, In «Architettura Intersezioni», n.1; 1998. Architettura grottesca, una non evitabile opportunità [Architecture grotesque, an unavoidable opportunity]. In Montuori, M., (edited by), Studi in onore di Giuseppe Samonà [studies in honour of Giuseppe Samonà], vol. 1; 1999. Chi ha paura del gusto cattivo? [Who's afraid of bad taste]. In ID, Litanie e griffonages, Roma. Edited by the authors of this paper is also the abstract Architetti senza Architettura. Nuovi scenari: dal paesaggio "popolare" alle "bidonvilles" [Architecture without Architects. New scenarios: from the 'popular' landscape to the slums] sent for the call to the international symposium Tradizione e modernità. L'influenza dell'architettura ordinaria nel moderno/ Tradition and Modernity. The influence of ordinar architecture in the modern (Iuav, 24 maggio 2014).
} 
a question of assuring these quality standards, which only three generations ago seemed to be irrenounceable common denominators ${ }^{8}$. The real challenge is to be able to imagine uses which offer intellectually stimulating options, in the belief that the production and consumption of cultural goods, of art, could constitute business, could ensure adequate economic returns, changing and evolving the common commercial standards.

Figure 6. People Lining for an Exhibition. The Anglo-Saxon Experience Teaches us that Museums Can Have Positive Financial Statements and that there is an Attractive Profit Margin

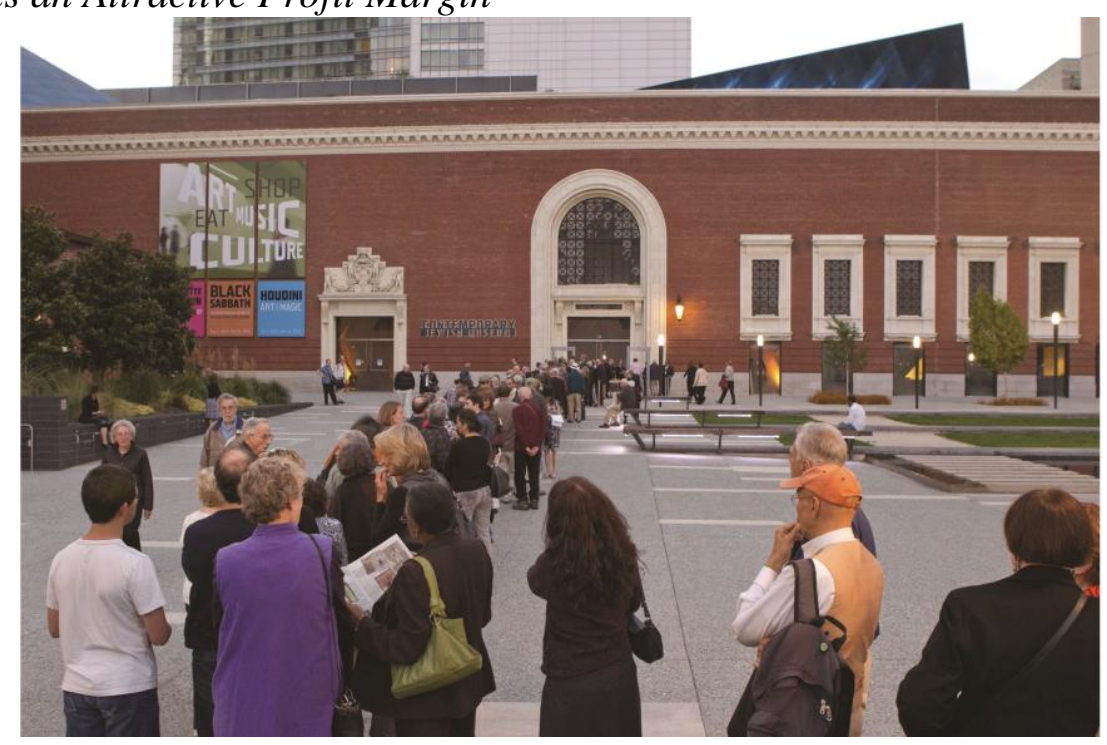

\section{Scenarios}

The great open spaces of Porto Marghera, the boundless empty sheds, horizontal silos, cooling towers, seem to be, by their very size, by the structural modularity that connotes them, by the undifferentiated availability of volumes, the perfect place to host functions related to training and the production and consumption of cultural goods. We could develop better this designation if we agreed on the definition of a Cultural Good understood, as was said before, as a Common Good, as a shared value for the community.

Venice is a capital that participates in the universal imagination, a placesymbol, reproduced in dozens of simulacra worldwide, a poignant collection of withered grace. A small city that is also a world capital. The proliferation of cultural events, exhibitions, conferences, concerts and shows appears totally out of proportion to the number of residents, but is in line with the vocation of the places, with the presence of two national and one international Universities, with the large Biennale programming and with the impressive flow of tourists

\footnotetext{
${ }^{8}$ Just think of the so-called popular housing finishes of the 1930s or, going further back in time, of the city apartment buildings, of the cast-iron fences of city parks, of the music gazebos, etc. In short, the reference is not under the banner of nostalgia for beautiful times that have passed, but of the civil consciousness that an architectural work, an urban environment, should be carried out to perfection.
} 
it attracts. In this respect it should be noted that the concentration of thirty million visitors per year seems untenable and that will require the relocation, to adjacent areas, of the centres of attraction.

One strongly suggestive scenario might be that of a City of Culture that could, with a gradual and planned colonization, settle in the areas of Porto Marghera, realizing sites for high level and specialized training and spaces for the production and consumption of the goods produced. We are thinking of the image, from figurative arts to advertising, design, cinema ${ }^{9}$, stage design, music, theatre, but also to the linked industries, from print shops to machine shops, to carpenter's workshops, photographic studios, etc. We are thinking of conference rooms, small, medium or large auditoriums, guest quarters, classrooms for lectures, workshops, laboratories, bars, canteens, restaurants, parks, greenhouses. A complex of settlements that require large surfaces and spacious interiors, volumes that are already present and easily adaptable, able to offer a compartment where it is also possible to realize economies of scale, restoring vitality and dignity to a particular urban fabric, in a state of progressive degradation.

Many projects have already been developed, on the occasion of graduation and workshops, but the necessary know-how to accompany these kinds of transformations is not the question; rather, there is a knotty problem which has now become essential and which must be solved in a hurry: will private national entrepreneurs know how to invest in Beauty and Culture, as is already occurring elsewhere ${ }^{10}$ ? Will politics manage to boost such investments with appropriate tax exemption manoeuvres for investment of this type? (Figure $7 \&$ 8)

We are confident that this conviction is growing, that more and more people are welcoming the idea that maintenance of the territory, recovering the existing buildings and relaunching Communication, Culture, Research and Art, are the driving forces of the future economy.

We only hope that the opportunity is grasped in time. The Angel of history flies into the future, but looks back to the past: it is from there that hope comes.

\footnotetext{
${ }^{9}$ Cinema which boasted a glorious tradition with the establishments of the Istituto Luce.

${ }^{10}$ The constructions that experiment with these settlement strategies have multiplied everywhere; we mention just a few among many: the Emsher Park in Duisburg (Germany) where the steel mill has been transformed into a vast leisure park with planned activities and services (by many local architect and later with the contributions of archistras like Herzog\&deMeuron, R. Koolhaas, N. Foster, etc); Acero Horno 3 (Monterrey, Mexico), where a mill has been transformed into a system of auditoriums by Grimshaw; or the less known waterfront park Sun Yat-sen Park in Zhong Shan (China) by landscapearchitecture office; or the many docks given back to the cities (London, Hamburg, Lisbon, etc); but also in the United States, from Washington to Detroit, and so on. And even in Italy there are examples: from the former cotton mill of Venice, today seat of the Iuav (By G. Valle), to the ex gasometer settlement of Bovisa, Milan Politecnico's premises; from the Montemartini electrical plant in Rome, now a branch of the Capitoline museums, to Bagnoli, whose buildings, formerly of the Ilva plant, are home to the Neapolitan Science Park, to the new Parco Dora in the industrial area of Turin, etc.
} 
Figure 7. Porto Marghera: Scenarios for Rehabilitating the Existing Buildings (Proposals Edited by Students of the Final Seminar Run by the Authors in 2000)


Figure 8. Porto Marghera: Scenarios for Rehabilitating the Existing Buildings (Manifestos for the W.A.Ve 2014, the Summer International Workshops of Venice Run by E. Giani. Images by D. Scomparin and D. Battilana)

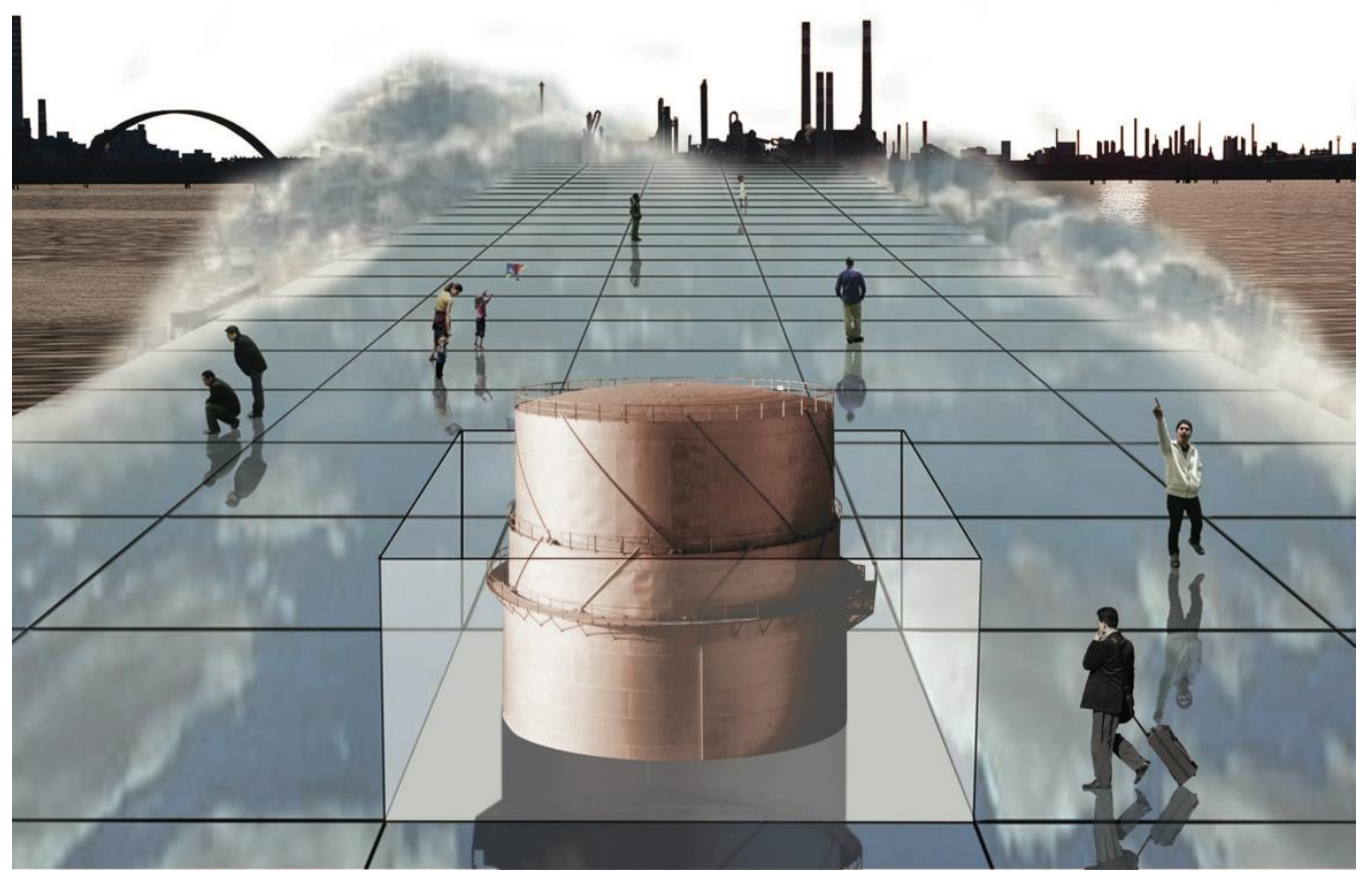




\section{Conclusion}

We express, in conclusion, an auspice and a prediction. taken.

The hope is for a higher 'quality' of the decisions that will be, finally,

It means no more occasional opportunism, nor collusion between privates and government as almost always happened in the past.

The auspice is the possibility to reverse these processes by adopting, with the correct methods and without distortions demagogic, a listening strategy. It means no more up-down decisions but bottom up strategies, preferring inductive paradigms to deductive ones.

The forecast is rather less optimistic.

We have already seen in the past as the darkest forces of the Market are able to take over 'high' social motivations and by defiling impulses and tendencies, turning every desire into business.

It could happen even with regard to the legitimate need of urban quality, of the abandoned heritage's aesthetic redemption.

It will be up to the called skills to arbitrate, by measure and firmness, the conflicting demands of the involved actors.

We only hope that the opportunity is grasped in time. The Angel of history flies into the future, but looks back to the past: it is from there that hope comes...

\section{Bibliography}

Bucaille, R., Pesez, J.M. Cultura materiale [material culture]. Enciclopedia Einaudi, Turin (Italian), Vol. V. IV, p. 271-305

Carnevale, G. 1984. L'architettura perde per distacco [The architecture loses for posting]. In «Confronto» n.3 (Italian)

Carnevale, G. 1989. Il grottesco prossimo venturo [The grotesque near future]. In Canestrari M. (edited by), Architettura e forma urbana [Architecture and urban form]. Clean, Neaples (Italian)

Carnevale, G. 1993. Caro studente ti scrivo [Dear student]. Cittàstudi, Milan (Italian)

Carnevale, G. 1993. Deformazioni ai margini [Deformation of the edge]. In «Op.cit.» n.76 (Italian)

Carnevale, G. 1995. Grottesco [Grottesque]. Definition for the Dizionario illustrato delle voci più utili all'architetto moderno [Picture dictionary of the terms most useful for modern architect], edited by Semerani L. Rizzoli, Bologna (Italian)

Carnevale, G. 1998. Inutilitas, infirmitas, foeditas, In «Architettura Intersezioni», n.1 (Italian)

Carnevale, G. 1999. Architettura grottesca, una non evitabile opportunità [Architecture grotesque, an unavoidable opportunity]. In Montuori, M. (edited by), Studi in onore di Giuseppe Samonà [studies in honour of Giuseppe Samonà], vol. 1 (Italian)

Carnevale, G. 2004. Litanie e griffonage, Officina edizioni, Rome (Italian)

Carnevale, G. 2004. Chi ha paura del gusto cattivo? [Who's afraid of bad taste]. In ID, Litanie e griffonages, op cit. 
Le Goff, J. 1978. Documento/Monumento [Monument/Document]. Enciclopedia Einaudi, Turin (Italian), vol. V, pp. 38-43

OuLiPo Ouvroir de litterature potentielle (http://oulipo.net/) 
